\title{
Music Therapy and Recovery in Mental Health: Seeking a Way Forward
}

\author{
Tríona McCaffrey ${ }^{1 *}$, Catherine Carr ${ }^{2}$, Hans Petter Solli ${ }^{34}$, Cherry Hense ${ }^{56}$ \\ 1 Irish World Academy of Music \& Dance University of Limerick, Ireland \\ 2 Unit for Social and Community Psychiatry, WHO Collaborating Centre for Mental Health Services \\ Development, Queen Mary University of London, United Kingdom \\ 3 Lovisenberg Diakonale Hospital, Oslo, Norway \\ 4 The Norwegian Academy of Music, Oslo, Norway \\ 5 Faculty of VCA \& MCM, The University of Melbourne, Australia \\ 6 Orygen, Centre of Excellence in Youth Mental Health, Melbourne, Australia \\ *triona.mccaffrey@ul.ie
}

Received: 27 March 2017 ; Accepted: 27 June 2017 ; Published: 1 March 2018

Editor: Avi Gilboa Reviewer: Kathy Murphy

\begin{abstract}
As recovery is a prevailing vision for modern mental health services internationally, it is timely to consider its current state of play in relation to music therapy practice. This paper offers a theoretical perspective of this topic, by presenting the views of four music therapy researchers situated in Australia, Ireland, Norway, and the United Kingdom. Each of the four authors completed doctoral research in music therapy in the past three years that is explicitly about, or related to, recovery in mental health. Collectively all authors have considerable experience of providing individual and group music therapy services in acute and community settings with adults and adolescents within recovery-oriented services. This article aims to elaborate on the implications of music therapy as a recovery-oriented practice, while presenting recommendations as to how music therapy can maximize support for recovery for our patients and service users. It draws on our respective doctoral study findings and lived experience of offering music therapy in recovery-oriented services, so as to present a collective theoretical perspective to other music therapy practitioners who are interested in this growing area. By doing so we hope to encourage discussion and response from music therapists practising in various mental health contexts in the service of developing the best possible music therapy services to our patients and service users.
\end{abstract}

Keywords: Mental health, well-being, recovery, music therapy

\section{Situating our text}

It is timely to consider the current state of play of recovery in relation to music therapy practice as recovery is a prevailing vision for modern mental health services internationally. This paper offers a theoretical perspective of this topic, by presenting the views of four music therapy researchers situated in Australia, Ireland, Norway, and the United Kingdom. Each of the four authors completed doctoral research in music therapy in the past three years that is explicitly about, or related to, recovery in mental 
health. Collectively all authors have considerable experience of providing individual and group music therapy services in acute and community settings with adults and adolescents within recovery-oriented services. This article aims to elaborate on the implications of music therapy as a recovery-oriented practice, while presenting recommendations as to how music therapy can maximize support for recovery for our patients and service users. It draws on our respective doctoral study findings and lived experience of offering music therapy in recovery-oriented services, so as to present a collective theoretical perspective to other music therapy practitioners who are interested in this growing area. By doing so we hope to encourage discussion and response from music therapists practising in various mental health contexts in the service of developing the best possible music therapy services to our patients and service users.

\section{Introducing Recovery}

The topic of mental health recovery is one that has gained increased attention in the music therapy literature (Chhina, 2004; Eyre, 2013; Kaser, 2011; Kooij, 2009; McCaffrey, Edwards, \& Fannon, 2011; Solli, Rolvsjord, \& Borg, 2013). Unlike traditional use of the term within psychiatry to describe the elimination of symptoms and restoration of social functioning, mental health recovery presents a way of thinking about and living beyond the confines of a diagnosis of mental illness (Shepherd, Boardman, \& Slade, 2008). The seeds of mental health recovery were sewn in the late 20th century by advocates of consumer and survivor movements of psychiatry who argued that people with severe mental illness had far more hopes and ambitions beyond being free of symptoms (Anthony, 1993). This is not to say that symptom reduction, or clinical recovery, is unimportant for personal recovery. Instead it is viewed as subordinate to personal and social aspects of well-being (Davidson \& Roe, 2007).

Since the 1980s a new understanding of 'recovery' began to emerge in the mental health literature. This moved beyond understanding recovery as an outcome that focused on extensive treatment in the hope of curing illness (Charland, 2012), and instead, related to a deeply personal journey that is embarked upon as one recovers their life beyond the confines of mental illness. Since that time, the recovery movement has challenged fundamental principles of the medical model, demanding changes to service delivery and treatment of those with mental illness. Such a position is not radically new in mental health care, and may be linked to earlier attempts to question covert power inequalities in society and more specifically within healthcare (Foucault, 1961/ 2001; Goffman, 1968). Indeed, through the process of deinstitutionalisation, mental health services have already been part of a huge shift in power relations, and it has been argued that a move to recovery orientated services may in fact be a further step in beginning to address the inequalities within wider mental health care (Anthony, 1993). Recovery implies “a 'bottom up' approach to service development, as it begins with the needs, preferences, and goals of the person in recovery" (Davidson, Tondora, Lawless, O'Connell, \& Rowe, 2009, p. 33). Such an approach offers a way of encompassing holistic, biographical and social data that can impact upon one's life circumstances (Fox, 2012). Conversely, where services have sought to transform provision to become more recovery-oriented, there have been critiques that through accommodating the wider needs of the professionals and services within these systems, the essence of each individual's recovery may be lost (Pilgrim \& McCranie, 2013; Rose, 2014).

Mental health recovery is not easy to define with completeness nor is it synonymous with cure. This is in part due to the heterogeneous nature of outcomes of mental illness, but also because of variations in its developments and applications within and between countries (Davidson, O'Connell, Tondora, Styron, \& Kangas, 2006; TurnerCrowson \& Wallcraft, 2002). One of the most commonly accepted definitions of recovery states that it is "a deeply personal, unique process of changing one's attitudes, values, feelings, goals, skills and/or roles" in order to live "a satisfying, hopeful, and contributing life" (Anthony, 1993, p.7). Recovery refers to the real life experience of the individual as one actively recovers "a new and valued sense of sense of self and 
or purpose" (Deegan, 1988, p.11). It is unlike rehabilitation where services support the social inclusion and autonomy of people with mental health problems through the active process of 'doing to'. This personal journey is exemplified through first-hand accounts of recovery where concepts of empowerment, self-help, and advocacy are emphasised in overcoming the limitations of mental illness (Chadwick, 2007; Davidson, 2003; Deegan, 1988; Repper, 2000; Ridgway, 2001). These narratives remind mental health practitioners that recovery is something that cannot be 'done to' another person but rather something that can be facilitated and supported.

The need for clarity and consensus around the meaning of recovery has been raised among the mental health community. In response to this, Leamy et al. (2011) carried out a narrative synthesis of 97 papers that described or developed an intellection of personal recovery from mental illness. The findings of this review were used to produce the CHIME conceptual framework that represents the processes of recovery to include: connectedness, hope and optimism about the future, identity, meaning in life, and empowerment. The main characteristics of the recovery journey were also identified as 1) an active process 2) individual and unique to the individual 3) non-linear, and 4) a journey of stages. The CHIME framework has since been validated in terms of its five key processes of recovery, however differences between this and the earlier review have been noted in relation to medication and diagnosis, practical support and scepticism (Bird et al., 2014). Such efforts to bring clarity to the term 'recovery' have been helpful while also serving as a reminder of the idiosyncratic nature of the recovery journey where varying cultural and contextual factors can feature.

Similar to the issue of consensus of definition, recovery also has posed challenges in terms of how it is realised in practice. At the heart of successful recovery-oriented practice is collaborative, respectful, and mutually trusting relationships between those who receive and deliver services (Slade, 2009). Hope, shared power, availability, openness, and stretching boundaries have been identified by service users as important ingredients of helpful relationships where recovery-oriented professionals have been described as courageous individuals who are willing to address the complexities and uniqueness of the change process in a collaborative manner (Borg \& Kristiansen, 2004). Repper and Perkins (2003) outlined the simplest and yet most essential part of the relationship between service user and professional is the acknowledgement of shared humanity:

The ability to recognize the humanity of those with whom we work, value them and recognize the importance of their lives forms the essential bedrock upon which supportive, hope-inspiring relationships are based. An individual is much more likely to begin to value himself/herself if others value him/her (p. 78).

A key concept of recovery-oriented practice is acknowledging that expertise may be present in multiple guises. Recovery acknowledges that expertise can be acquired through skill and/or training but also through lived experience (Greenhalgh, 2009; Shepherd et al., 2008; Telford \& Faulkner, 2004). Acceptance of these expertise manifestations demands renegotiation of power, whereby the power differential of the doctor-patient relationship traditionally espoused in the medical model is ameliorated (Kaminskiy, Ramon, \& Morant, 2012). In a recovery-oriented context the individual's lived experience becomes a source of shared expertise, directing decisions made in partnership with professionals about the care that is received. This fosters collaborative working between all parties concerned but on a deeper level, a shared sense of humanity in the task of overcoming adversity. Such a shift in power differentials can pose a challenge to mental health professionals as it may be construed as devaluing the role of professional expertise and practice. Likewise, it can be challenging for service users who have traditionally trusted in expert advice of mental health professionals to find that, in recovery-oriented services, their lived expertise is a central source of information in deciding next steps of their care pathway. Therefore, the delivery of person-centred health provision informed by multiple genres of expertise is neither simple nor straightforward. 
Several approaches to recovery-oriented care have been developed, manualised, tried out and evaluated, such as REFOCUS, CHIME and INSPIRE (Slade \& Wallace, 2017) however, these are primarily team-level practices with special focus on careplanning. Hence, the present text is a contribution to widen the perspective of how one therapeutic approach- music therapy- may provide support for recovery, whilst holding in mind that music therapy is also often integrated as part of interdisciplinary work.

\section{An overview of our research and implications for recovery}

Within the authors' collective research to date, all have focused upon the role and meaning of music therapy in mental health care and to varying degrees, the role and implications for recovery within this. Independently of each other, the authors recognised the absence of service users' voices and views from music therapy literature, a feature perhaps symbolic of the emphasis of professional-as-expert. Underpinned by the inclusive and collaborative message of mental health recovery, each of the authors sought, in differing ways, to welcome service user perspectives of music therapy as a valuable source of knowledge to inform practice. The following section provides succinct overviews of our doctoral studies and their related findings that support the concept of music therapy as a recovery-oriented practice.

McCaffrey's (2014) doctoral study aimed to develop high-quality processes for service user evaluation of music therapy in mental health while reflecting upon the elicited feedback to gain a deeper understanding of how music therapy is received among those who have attended sessions in mental health. Using both verbal and arts-based evaluation processes that encompassed the views of nine service users, many findings closely aligned to characteristics of recovery-oriented practice. These included that: music therapy is attended because of a love or interest in music; there is not always a distinction between music therapy and other music activities; music therapy is a health-promoting resource, musical contribution is fostered in a group setting; and that the music therapy environment is person-centred. Findings also uncovered some service users' challenges when first becoming involved in music therapy but also feelings of tension and frustration when unfamiliar ways of engaging with music are presented within sessions. These later aspects of personal experience in sessions were relatively unnoticed in the music therapy literature at the time of this study's conclusion. Overall, this study sought to honour and tune into service user perspectives as a valuable source of knowledge to inform music therapy practice.

Carr's doctoral research (2014) sought to explore processes and outcomes of acute inpatient groups, integrating therapist and service users' views and integrating quantitative and qualitative methods. Service users described three core processes of music therapy: finding a means to engage with therapy and others, connecting to and expressing emotions, and building awareness of and making contact with others. Across these processes, service users described a myriad of changes beyond psychiatric symptoms that were of high individual importance. The attributions participants gave for change involved autonomous experiential learning ie. learning by doing, with support and encouragement from the therapist (as opposed to teaching) and creation of a safe space that afforded opportunities for creativity.

Solli's doctoral study (2014) explored the user perspective of inpatients diagnosed with psychosis. The study included a meta-synthesis of previous research containing mental health service users' first-hand accounts of experiences with music therapy (Solli, Rolvsjord, \& Borg, 2013). Here it was found that service users primarily experience music therapy in terms related to positive mental health and well-being (such as having a good time, being together, feeling, and being someone) and only occasionally in terms of symptom remission. Further, two case studies of patients admitted to a psychiatric intensive care unit were conducted, based on participatory observation and qualitative interviews of nine inpatients hospitalised at a psychiatric intensive care unit (Solli \& Rolvsjord, 2015; Solli, 2015). The participants here described music ther- 
apy in terms of freedom, contact, well-being, and symptom relief, and illuminated music therapy's unique possibilities to afford agency and empowerment, promote a positive identity, develop positive relationships, and expand social networks. The study concluded that music therapy affords a therapeutic and social arena where people with mental health difficulties can work on their process of recovery, and hence is congruent with recovery-oriented practice.

Hense's doctoral study (2015c) investigated how young people's musical identities changed during experiences of, and recovery from, mental illness. Her participatory research design aimed to align with recovery principles (Hense \& McFerran, 2016; Hense, McFerran, Killackey, \& McGorry, 2016) by involving young people as collaborators through feminist informed qualitative interviews (Hense, 2015a) and holding an agenda of action-based outcomes from the findings (Hense, 2015b). The first cycle of research resulted in a constructed grounded theory illustrating how young people came to music therapy with musical symptoms that expressed aspects of their illness and subsequently utilised music therapy to transition these experiences into everyday forms of music participation (Hense, McFerran, \& McGorry, 2014). In line with recovery processes, young people described wanting to use their music as means for ongoing participation in the community, which resulted in the formation of the Youth Music Action Group to address gaps in local music opportunities for young people with experiences of mental illness (Hense, 2015b).

Although our respective doctoral research pursued different questions concerning identity, lived experience, process, outcomes, and evaluation of music therapy in mental health, each of the authors agreed that our studies were underpinned by the common thread of mental health recovery. This is exemplified in each of our efforts to foster the inclusion of service user voices in our respective studies. Having outlined our individual approaches to practice and considered our research positions and findings, the next section will draw upon our collective knowledge and experience to reflect on how music therapy can support mental health recovery.

\section{How can music therapy support recovery?}

Whether music therapy be offered in a mental health institution or in a community setting, we are of the view that the core of our role involves building trust and relationships with individuals, providing a space for musical expression and reflecting upon this in the context of what the individual feels is relevant and needed in that moment (Carr, Odell-Miller, \& Priebe, 2012; Carr, 2014). For some, this may be a need to be heard, or an experience of a different state, for example, peace. For others, therapy means having the space to be listened to, for concerns to be thought about and advocated for with the wider multidisciplinary team. Across all this work, the musical relationship provides opportunities for service users to find ways of managing their distress, to reflect upon relationships with others, and to communicate experiences that are not always easily put into words. Within this section we focus upon ways of working that may be specifically conducive to the recovery approach while at the same time acknowledging that recovery is not the job of professionals, the mental health system, nor is it a treatment ideology (Ness, Borg, Semb, \& Karlsson, 2014). Hence, it is not our job as music therapists to recover people because within this paradigm people cannot be recovered as life is not an outcome (Davidson, Tondora, \& Ridgeway, 2010).

The authors are mindful that attempts to adapt recovery as a model in psychiatric practice has led to claims about the original notion of recovery being "hijacked" (Mental Health Recovery Study Working Group, 2009). Likewise, it is acknowledged that the desire to 'model' recovery has been perceived as a threat to creating an authentic recovery-based framework (Glover, 2002). However, as recovery is increasingly being applied by mental health stakeholders internationally to describe overall vision and aims of practice (WHO, 2013; Slade, Adams, \& O'Hagan, 2012), we see that there is a need for music therapists to take stock of this international development towards overall recovery-oriented service provision. It is also an ideal opportunity to reflect upon 
how music therapy can play a leading role in contributing to the transformation of traditional service provision towards ideologies connected to the ideas of personal recovery.

Practising in a recovery congruent way may not involve 'new' models of music therapy. However, it involves a radical shift in focus, from targeting deficits and function as seen from the point of view of service systems and professionals to start placing the person at the centre and acknowledging mental health problems as both personal and social (Hummelvoll, Karlsson, \& Borg, 2015). Existing literature stemming from anti-oppressive (Baines, 2013), feminist (Hadley, 2006), resource-oriented (Rolvsjord, 2010), community music therapy (Stige \& Aarø, 2012), and the empowerment perspective (Rolvsjord, 2004) detail how music therapy can not only involve critical consciousness raising to support the ethos of recovery but also counteract objectifying practice and behaviours embedded in the medical model of mental health systems. We propose four central ways of maximising support for recovery in music therapy practice.

\section{Recognising and respecting expertise by experience}

Our first recommendation for providing music therapy in a recovery-oriented context is that service users are regarded as 'experts by experience'. A central assumption in mental health recovery is that service users acquire expertise as a consequence of living with mental illness (Anthony, Rogers, \& Farkas, 2003). This expertise also extends to knowledge that is assimilated as a result of one's direct involvement with mental health services and service users' rights to have an equal stakeholder voice therein. Such a stance positions service users as equal partners in the treatment process whereby personal expertise by experience meets professional expertise by skill and/or training. This viewpoint, serves to remind practitioners that service users are the first and foremost point of knowledge in terms of understanding factors that may hinder or foster a personally fulfilling and meaningful life and the priorities placed upon them. This openness to being led by the views and wishes of the service user is vital when approaching music therapy as recovery-oriented practice. On an organisational level, practical implications for acknowledgement of service users' expert role include to start involving service users and user organisations in the development of music therapy services. Another possibility, perhaps most relevant in community services, is to include service users or people with user-experience as co-facilitators or partners.

\section{Awareness and integration of processes at the core of recovery}

Recovery-oriented practice is recognised by a focus on supporting personally defined recovery where "individuals are supported to define their own needs, goals, dreams, and plans for the future to shape the content of care" (Le Boutillier et al., 2011, p. 1474) rather than by generalised and manualised interventions based on diagnosis and function. Hence, focusing on factors that promote recovery means treatment goals and approaches in music therapy should as far as possible be determined in mutual collaboration with the therapist on the basis of the person's own preferences. In addition, we propose that music therapists are mindful of the five key processes that have been found central to the recovery journey and recommend the aforementioned CHIME conceptual framework as a valuable source of synthesised knowledge in this regard (Leamy et al., 2011). Based on service users' own personal experiences of recovery, the five recovery processes are:

1. Connectedness (Peer support and support groups, relationships, support from others, being part of the community).

2. Hope and optimism about the future (belief in possibility of recovery, motivation to change, hope-inspiring relationships, positive thinking and valuing success, having dreams and aspirations. 
3. Identity (dimensions of identity, rebuilding/redefining positive sense of identity, overcoming stigma).

4. Meaning in life (meaning of mental illness experiences, spirituality, quality of life, meaningful life and social roles, meaningful life and social goals, rebuilding life)

5. Empowerment (personal responsibility, control over life, and focusing upon strengths).

We agree with authors of this conceptual framework who posit that one possible way to approach recovery in mental health practice is to evaluate practice in terms of its impact on these five named processes (Leamy et al., 2011). Interestingly, but maybe not so surprisingly, studies of service users' experiences of music therapy convey narratives of recovery that are congruent with those of the CHIME study (Ansdell \& Mehan, 2010; Carr, 2014; Hense, McFerran, Killackey, \& McGorry, 2016; McCaffrey \& Edwards, 2015; McCaffrey \& Edwards, 2016; Rolvsjord, 2010; Solli, Rolvsjord, \& Borg, 2013; Solli \& Rolvsjord, 2015). This suggests that there is already some resonance between some established central processes of recovery and personal accounts of how service users experience music therapy in practice. Such resemblance highlights the potential that music therapy may have in supporting service users on their recovery journey.

\section{Being resource-oriented}

As recovery emphasises the individual's personal autonomy and strengths, we recommend that the overall aims, goals and objectives of therapy promote service users' resources and goals rather than highlighting perceived deficits or weaknesses as traditionally encompassed by a medical model of practice (Davidson, 2003; Davidson \& Roe, 2007). In developing a protocol for resource-oriented music therapy, Rolvsjord, Gold, and Stige (2005) described six essential therapeutic principles for music therapy which included: 1) to focus on the client's strengths and potential, 2) to recognise the client's competence related to his or her therapeutic process, 3) to collaborate with the client concerning the goals of therapy and the methods of working, 4) to acknowledge the client's musical identity, 5) to be emotionally involved in the music, and 6) to foster positive emotions. We put forward these six guiding principles to amplify service user resources so as to ameliorate against the potentially limiting impact of mental illness. Simultaneously, these principles help to identify and build on a person's strengths and interests in order for the person to have an identity and a life beyond the label of being mentally unwell (Davidson \& Roe, 2007). Many examples of resource-oriented practice have been offered by Rolvsjord (2010). Other leading mental health professionals have acknowledged the resource-oriented capacity of creative music therapy in encouraging expressive skills, personal growth, and autonomy (Priebe, Omer, Giacco, \& Slade, 2014).

It is important to clarify that a strong focus on the person's resources in music therapy does not imply avoidance of problems and illness, as has been an expressed concern in relation to a resource-oriented practice (Pedersen, 2014). Rather, we argue in line with Rolvsjord (2010) that there is a need for a better balance between the focus on resources and problems, as both are always interacting aspects in the therapeutic process. However, as many service users are struggling with stigma, hopelessness and low motivation (Slade, 2009), we argue that a greater focus on wellbeing and positive aspects of mental health in music therapy is warranted.

\section{Being community-oriented}

As people with mental health problems often experience stigma, disempowerment, and social exclusion, processes of recovery are closely interlinked with social processes of change (Onken, Craig, Ridgway, Ralph, \& Cook, 2007; Repper \& Perkins, 2003). Hence, a core aim of recovery-oriented services is to support people who live with mental illness to reintegrate into society and to live as equal citizens (Le Boutillier et 
al., 2011). In accordance with this, there has been a decentralisation and deinstitutionalisation of mental health care, and mental health services are more often provided in the community. Music therapy has shown to be a good arena for developing positive relationships with others, expanding social networks, and to help with the transition from hospital settings to everyday life in various social and cultural arenas (Ansdell \& DeNora, 2016; Jampel, 2007; Rolvsjord, 2013; Solli, 2015). We propose that to maximize support for recovery, music therapy needs to include an orientation towards social participation and inclusion. This ethos does not dismiss the notion of recovery-oriented practice being carried out in acute settings where wider social and community contacts are limited. Rather, it is encouraged that in such circumstances that social contact and preservation of community links are promoted as far is possible.

Practical implications of a stronger community orientation include taking music therapy out of the music therapy room and into various social arenas, either within an institution or in the community itself. Here it is possible to expand music therapeutic practice to include active music making in as choirs or bands, and to include performances and projects in public spaces (Jampel, 2007; Ansdell \& DeNora, 2016).

To propose that working in recovery-congruent ways is new to music therapy, would dismiss decades of valuable discourse and work. For example, within the UK, Mary Priestley documented running open performative music groups that included staff within the hospital institution (Priestley, 1994). However, examination of some of the principles guiding different music therapy approaches used in mental health care suggests that a recovery-congruent approach may not always easily align with the theoretical premises underpinning such approaches. It is therefore perhaps not surprising that later evolutions of music therapy that have emerged in the context of more critical interdisciplinary dialogue about health in society bear greater synergy to recovery philosophy and indicate an increasing engagement with recovery-congruent ways of working.

\section{Bringing recovery ideology to reality: Issues and concerns}

In this final section, we draw on our collective experience as music therapy practitioners and researchers who have advocated for the realisation of a recovery-oriented approach at mental health services in our respective countries. In particular we bring to discussion some of the challenges and concerns that each of us have encountered through practice but also through processes of inquiry that have been aligned within the recovery tradition (Carr, 2014; Hense, 2015a, 2015b, 2015c; Hense, McFerran, \& McGorry, 2014,, 2016; McCaffrey, 2014; McCaffrey \& Edwards, 2016; Solli, Rolvsjord, \& Borg, 2013; Solli \& Rolvsjord, 2015; Solli, 2015).

An often mooted concern around recovery is that placing service users as experts by experience can devalue the training and expertise of mental health professionals. While acknowledging the benefits of self-help and peer support, we believe that the potential contribution of professional help should not be devalued in striving towards a more recovery-oriented system. Recovery directly challenges traditional notions of the source of expertise and demands that mental health professionals recognise and learn from service users' own knowledge about themselves, their needs, and skills. This means acknowledging the limitations of our own training, knowledge, skills, and strategies for change in directly meeting each unique individual. It requires prioritisation of close and careful attention to what service users appraise as important and necessary.

As Deegan (2003) pointed out, "people in recovery and the mental health professionals can work together to expand opportunities for recovery" (p.374). Rather than devaluing, we are of the view that such a model of working places a greater responsibility for therapists to have the skills and competencies to communicate and respond with sensitivity, collaborate and empower individuals in decision making. While challenging, this is of utmost relevance particularly when service users are at their most vulnerable and may not be able to easily articulate thoughts, feelings, or needs. Within the UK, such skills and competencies are highlighted by national guidelines (NICE, 
2011) and within the regulatory body of music therapists (HCPC, 2013) including the competency to base relationships with service users "on mutual respect and trust," (p.7) "'to communicate effectively (p.9), and to work "in partnership with service users, other professionals, support staff and others" (p. 10).

A related concern to that of devaluing professional training and expertise, might be expressed regarding the interface between music therapy and wider community music services. Thinking again about power relations, the changing emphasis from experts 'doing to' to 'working in partnership' to define needs of care (Gilburt, Slade, Bird, Oduola, \& Craig, 2013), could lead, for example, to service users opting to access participatory music over music therapy as a means of continuing wellbeing. Does the adoption of recovery-oriented services therefore pose a threat to traditional models of music therapy? Research on service users' experiences of music therapy in mental health care suggests otherwise, in that there is still a clear role for music therapy as one means of enabling a reconnection with musical resources (Ansdell \& Meehan, 2010; Carr, 2014; McCaffrey \& Edwards, 2016; Solli, 2014; Solli, Rolvsjord, \& Borg, 2013; Solli \& Rolvsjord, 2015). These studies suggest music therapy is often seen within a continuum of ways in which music can be used to support mental health (Ansdell, 2015; Ansdell \& Meehan, 2010; Carr, 2014; McCaffrey et al., 2011). Rather than pose a threat, recovery-orientation opens up an opportunity to consider the wider possibilities of how the spectrum of music therapy - community music therapy - community and participatory music services might work together in supporting clients and communities. Issues and opportunities arising from this are illustrated and considered in the following scenarios:

\section{Scenario 1}

A service user identifies that they currently feel isolated in their consultation with the psychiatrist. The service user is a skilled musician but has ceased to play with others after onset of acute symptoms which led to a breakdown in relationships with other musicians in their group. The person has encountered many types of psychological therapy over the years and currently has no wish to engage in further therapy. The psychiatrist is not familiar with arts opportunities in the community but is aware of a music therapy group and suggests this might be beneficial.

In this scenario, whilst the psychiatrist is working with the service user's own identified needs, at this time, the service user has no wish to enter into therapy. A referral to music therapy might not be the best way forward if the person does not wish or feel ready to enter into this to explore relational issues in depth with others in a group. Conversely, whilst support to access community based music opportunities may be an alternative means of addressing isolation, this person again, may feel vulnerable about returning to making music with others. A recovery-oriented response, might be the psychiatrist explaining this in more detail to the person and asking for their views and preferences. They might jointly agree for the psychiatrist to put them in touch with the music therapist to speak further about possibilities for individual music therapy or explore alternative creative lessons or groups available in the local area.

\section{Scenario 2}

A service user is about to be discharged from hospital. She has accessed an open music therapy group on the ward for the first time and found this helpful. For the first time, she has sung in a group and identified that this makes her feel good and is a way to get to know and be with others. She wishes to continue musical participation but is anxious about how she might manage this and staying well on discharge. The music therapist discusses options available with the service user and they jointly agree for her to be referred to a music therapy group in her local area on discharge and for the music therapist to liaise with her occupational therapist and care coordinator to help them identify a local choir linked to wider community initiatives. 
Here, the service user has had a helpful experience of music therapy, wishes to continue but also has recognised for the first time, ways in which music and wider music participation might support her recovery. The multidisciplinary team work together with the service user to ensure she is supported post-discharge through referral to a music therapy group. The team recognise her wish for wider musical participation in the community as a resource she has identified for support in her recovery and together provide signposting and support to access this.

\section{Scenario 3}

A lady with a long history of service use is admitted to an acute ward due to increased agitation at home. She can communicate verbally but her speech is not always clear and can be difficult to understand. She joins the open music therapy group and participates fully in the music-making. During the admission her medication is changed to a daily injection, which she experiences as painful, frightenin,g and makes her fearful and angry at nursing staff. She begins to shout and fight staff, throwing objects at them. As a result, she is put onto continual staff observation and is unable to leave her room. Staff members are fearful of her and cease to listen to what she is communicating. The music therapist offers individual sessions with the observing staff member present which she agrees to with enthusiasm. The therapist does not bring small instruments in case she attempts to throw these at staff but brings a guitar which they are able to share. They sit together on the floor and improvise songs together. Afterwards, she says these songs give her strength and expresses her anger at what is happening to her. The therapist notices that it takes a long time for the lady to be ready to end the sessions. She shares this observation with the lady and wonders if access to music at other times of the week might be helpful? The lady agrees fully, so the therapist advocates for access to a CD player with the nursing staff. She is given access to this, along with occupational therapy assistants visiting to play CDs and sing together. The following week, the lady is taken off observation. She re-joins the music therapy group and expresses appreciation for both the access to music and the opportunity to connect to feelings of strength as a means of internal support.

This final scenario suggests a number of issues in relation to the interplay between expertise and collaboration to meet presenting needs. The medical team recognise that her medication needs to be changed, but the service user experiences this as frightening and painful. Her resulting response prevents her from accessing a resource (music therapy group) which she uses regularly and leads to a dynamic of fear between both service user and staff. The therapist formulates an opinion as to what might be happening in their sessions, but is led first and foremost by what is communicated by the service-user herself and checks in with the service user as to whether this is what she herself, feels she needs. The therapist recognises the importance of connecting to an internal resource (strength) at this time of stress and supports this musically. She advocates for the service user, negotiating access to an object with staff, explaining the risks and benefits and offering suggestions to staff as to how to mitigate risks. By recognising the importance of 'strength' and promoting access to music, the service user suggests the experience gave her hope and a different means of interacting with and connecting to staff beyond the difficult and frightening experiences of being given medication.

Across all three scenarios, such discussions are dependent upon the availability and awareness of resources both within and outside the healthcare system and an openness and willingness of professionals to listen to and support service users in making their needs and preferences known. They are also dependent upon the level and depth of therapeutic work the service user wishes to have and is ready to enter into. The scenarios underpin the complexity of the shift required of professionals and services operating within the medical model alone, to become more recovery-orientated as a service. Morant's study (2006) identified how mental health practitioners are continually faced with navigating such tensions through 'compromise solutions', often balancing seemingly incompatible social representations (for example, evidence base, local policy and 
service user and carer views) to identify how best to meet service users' needs. Dilemmas described in Morant's study included conflicting information regarding the best treatment options available for service users, remaining person-centred, and balancing needs as defined within the medical model with wishes that may not be easily met by medical services alone but are identified as important, if not more so by the users of these services.

\section{Conclusion}

When commencing this paper, the authors recognised that little collective discussion has occurred in the literature to date about music therapy and mental health recovery. Therefore this paper was written with the aim of commencing such a theoretical discussion with the hope of stimulating wider and enlivened debate about this topic among music therapists working in this field. Our collaboration as authors of this paper required much reflection, time, and negotiation in our endeavour to scaffold a theoretical framework around recovery-oriented music therapy in mental health. It demanded patience as we gained an understanding of each other's professional and lived expertise of working in recovery-oriented mental health services in different corners of the world. Most difficult of all was overcoming our concerns that in publishing this paper, we would outline a differing approach to music therapy provision than peers who have adopted a treatment-based and indeed dominant approach to practice that is heavily influenced by the medical-model. In many ways our experiences of writing this paper mirror some vital components of recovery-oriented relationships between service users and staff where flexibility, negotiation, and collaboration feature within a framework that offers an alternative way forward. Furthermore, we also became acutely aware that there are many layers of recovery, from that which is held and owned by service users, to service awareness and responsiveness, team interactions but also recovery as encompassed in music therapy.

We concur with the view that emerging discussions and use of the recovery model in music therapy "represents in our view something of a recovery of the core of music therapy practice, theory and research itself" (Ansdell \& DeNora, 2016, p. 224). This suggests that recovery orientation moves beyond professional practice to the central beliefs and value systems of music therapists (Slade, Amering \& Oades, 2008; Borg \& Kristiansen, 2004). Such values are congruent with those of social justice (Curtis, 2012; Vaillancourt, 2012) and anti-oppressive practice (Baines, 2013). Likewise we acknowledge that some existing models of music therapy may be challenged more so than others to fully encompass the principles we have described in this paper. This may be relevant to behavioural, psychoanalytic, psychodynamic, and other approaches to music therapy practice in mental health that are aligned to principles of the medical-model where clinical recovery and professional expertise are emphasised at the risk of devaluing service users' lived experience. We acknowledge that music therapists working within such models may already be adapting their practice to incorporate these principles and hope that this paper may serve as a means of encouraging further sharing of ideas, challenges, practice, and discussion. Recovery orientation suggests a balance of the therapist's formulation and practices with ongoing dialogue with service users to reach a shared understanding of current issues, needs and ways in which music therapy, community music or wider psycho-social programmes might help to address and meet these. It demands that therapists acknowledge resources and potential of service users and the importance of connectedness, hope, identity, meaning in life, and empowerment (CHIME) beyond deficits or pathology alone. As such, a recovery-oriented approach suggests a meeting of two experts- professional and service user. Such an approach requires an integrated recovery-oriented approach across services, yet offers the potential for much richer, nuanced and person-centred options to support service users throughout their recovery. 


\section{Acknowledgements}

Our thanks are due to Professor Randi Rolvsjord, the Grieg Academy, University of Bergen, for being a critical friend in preparing this paper.

\section{References}

Ansdell, G. (2015). How music helps in music therapy and everyday life. Farnham, England: Ashgate.

Ansdell, G., \& Meehan, J. (2010). Some light at the end of the tunnel. Music and Medicine, 2(1), 29-40, https://dx.doi.org/10.1177/1943862109352482.

Ansdell, G., \& DeNora, T. (2016). Musical pathways in recovery. Community music therapy in mental wellbeing. New York, NY: Routledge.

Anthony, W. A. (1993). Recovery from mental illness: The guiding vision of the mental health service system in the 1990s. Psychiatric Rehabilitation Journal, 16(4), 11-23, http://psycnet.apa.org/doi/10.1037/h0095655.

Anthony, W. A., Rogers, E. S., \& Farkas, M. (2003). Research on evidence-based practices: Future directions in an era of recovery. Community Mental Health Journal, 39(2), 101-114, https://dx.doi.org/10.1023/A:1022601619482.

Baines, S. (2013). Music therapy as an anti-oppressive practice. The Arts in Psychotherapy, 40, 1-5, https://dx.doi.org/10.1016/j.aip.2012.09.003.

Bird, V., Leamy, M., Tew, J., Le Boutillier, C., Williams, J., \& Slade, M. (2014). Fit for purpose? Validation of a conceptual framework for personal recovery with current mental health consumers. Australian and New Zealand Journal of Psychiatry, https://dx.doi.org/ 10.1177/0004867413520046.

Borg, M., \& Kristiansen, K. (2004). Recovery-oriented professionals: Helping relationships in mental health services. Journal of Mental Health, 13, 493-505, https://dx.doi.org/10.1080/ 09638230400006809.

Carr, C. (2014). Modelling of intensive group music therapy for acute adult psychiatric inpatients. London, England: Queen Mary University of London.

Carr, C., Odell-Miller, H., \& Priebe, S. (2012). A systematic review of music therapy practice and outcomes with acute adult psychiatric in-patients. PLOS ONE, 8(8), e70252, https://dx.doi.org/10.1371/journal.pone.0070252.

Chadwick, P. K. (2007). Peer-professional first-person account: Schizophrenia from the inside-phenomenology and the integration of causes and meanings. Schizophrenia Bulletin, 33, 166-173, https://dx.doi.org/10.1093/schbul/sbl034.

Charland, L. (2012). Benevolence and discipline: the concept of recovery in early nineteenthcentury moral treatment. In A. Rudnick (Ed.), Recovery of people with mental illness : Philosophical and related perspectives (pp. 65-67). Oxford: Oxford University Press. https://doi.org/10.1093/med/9780199691319.003.0005.

Chhina, C. (2004). Music therapy and psychosocial rehabilitation: Towards a person-centered music therapy model. Canadian Journal of Music Therapy, 11, 8-30.

Curtis, S. (2012). Music therapy and social justice: A personal journey. The Arts in Psychotherapy, 39, 209-213, http://dx.doi.org/10.1016/j.aip.2011.12.004.

Davidson, L. (2003). Living outside mental illness: Qualitative studies of recovery in schizophrenia. New York, NY: NYU Press.

Davidson, L., O'Connell, M., Tondora, J., Styron, T., \& Kangas, K. (2006). The top ten concerns about recovery encountered in mental health system transformation. Psychiatric Services, 57, 640-645, https://dx.doi.org/10.1176/appi.ps.57.5.640.

Davidson, L., \& Roe, D. (2007). Recovery from versus recovery in serious mental illness: One strategy for lessening confusion plaguing recovery. Journal of Mental Health, 16(4), 459-470, https://dx.doi.org/10.1080/09638230701482394. 
Davidson, L., Tondora, J., Lawless, M. S., O'Connell, M. J., \& Rowe, M. (2009). A practical guide to recovery-oriented practice: tools for transforming mental health care. New York, NY: Oxford University Press. pp. 33-61.

Davidson, L., Tondora, J., \& Ridgeway, P. (2010). Life is not an "outcome": Reflections on recovery as an outcome and as a process. American Journal of Psychiatric Rehabilitation, 13(1), 1-8, http://dx.doi.org/10.1080/15487760903489226.

Deegan, P. E. (1988). Recovery: The lived experience of rehabilitation. Psychosocial Rehabilitation Journal, 11(4), 11-19, http://psycnet.apa.org/doi/10.1037/h0099565.

Deegan, G. (2003). Discovering recovery. Psychiatric Rehabilitation Journal, 26, 368-376, http://psycnet.apa.org/doi/10.2975/26.2003.368.376.

Eyre, L. (2013). Adults in a recovery model setting. In L. Eyre (Ed.), Guidelines for music therapy practice in mental health (Adobe Digital Editions version). Gilsum, NH: Barcelona. http://www.barcelonapublishers.com/e-books.

Foucault, M. (1961/2001). Madness and civilization: A history of insanity in the age of reason. Oxon, UK: Routledge. https://doi.org/10.4324/9780203278796.

Fox, J. (2012). The recovery concept: The importance of the recovery story. In S. Walker (Ed.), Modern mental health: Critical perspectives on psychiatric practice (pp. 49-64). Albans, UK: Critical Publishing Ltd.

Gilburt, H., Slade, M., Bird, V., Oduola, S., \& Craig, T. K. J. (2013). Promoting recoveryoriented practice in mental health services: A quasi-experimental mixed-methods study. BMC Psychiatry, 13, 167, https://dx.doi.org/10.1186/1471-244X-13-167.

Glover, H. (2002). Developing a recovery platform for mental health service delivery for people with mental illness/distress in England: A discussion paper. United Kingdom: National Institute of Mental Health.

Goffman, E. (1968). Asylums: Essays on the social situation of mental patients and other inmates. London, England: Penguin group.

Greenhalgh, T. (2009). Patient and public involvement in chronic illness: Beyond the expert patient. BMJ: British Medical Journal, 338, 629-631, http://dx.doi.org/10.1136/bmj.b49.

Hadley, S. (2006). Feminist perspectives in music therapy. Gilsum, NH: Barcelona Publishers.

Health and Care Professions Council (HCPC), (2013). Standards of proficiency- Arts Therapists. Retrieved from http://www.hpc-uk.org/publications/standards/index.asp?id=39.

Hense, C. (2015a). Feminist-informed collaborative interviews with young people recovering from mental illness. In C. Hense, G. McGibbon, C. Philips, \& S. Rudolf (Eds.), Researching for Social Change (pp. 15-32). Melbourne: Melbourne University Social Equity Institute.

Hense, C. (2015b). Forming the youth music action group. Voices: A World Forum for Music Therapy, 15(1), https://dx.doi.org/10.15845/voices.v1i1.810.

Hense, C. (2015c). Musical identities of young people recovering from mental illness. University of Melbourne, Australia. Unpublished doctoral thesis, Retrieved from, http://hdl.handle.net/ $11343 / 55361$.

Hense, C., \& McFerran, K. S. (2016). Toward a critical grounded theory. Qualitative Research Journal, 16(4), 402-416.

Hense, C., McFerran, K. S., \& McGorry, P. (2014). Constructing a grounded theory of young people's recovery of musical identity in mental illness. The Arts in Psychotherapy, 41, 594-603, https://dx.doi.org/10.1016/j.aip.2014.10.010.

Hense, C., McFerran, K. S., Killackey, E., \& McGorry, P. (2016). Youth Voice Journal. Retrieved from, https://youthvoicejournal.com/2016/02/03/.

Hummelvoll, J. K., Karlsson, B., \& Borg, M. (2015). Recovery and person-centredness in mental health services: Roots of the concepts and implications for practice. International Practice Development Journal, 5, Suppl 7.

Jampel, P. (2007). Performance in music therapy with mentally ill adults. New York, N.Y: New York University. Unpublished doctoral dissertation. 
Kaminskiy, E., Ramon, S., \& Morant, N. (2012). Exploring shared decision making for psychiatric medication management. In S. Walker (Ed.), Modern mental health: Critical perspectives on psychiatric practice (pp. 33-48). Albans, UK: Critical Publishing Ltd.

Kaser, V. (2011). Singing in the recovery model with a chronic mentally ill offender. In A. Meadows (Ed.), Developments in music therapy practice: Case study perspectives (pp. 400-415). Gilsum, NH: Barcelona.

Kooij, C. V. (2009). Recovery themes in songs written by adults living with serious mental illnesses. Canadian Journal of Music Therapy, 15, 37-58.

Leamy, M., Bird, V., Le Boutillier, C., Williams, J., \& Slade, M. (2011). Conceptual framework for personal recovery in mental health: Systematic review and narrative synthesis. The British Journal of Psychiatry, 199, 445-452, https://dx.doi.org/10.1192/bjp.bp.110.083733.

Le Boutillier, C., Leamy, M., Bird, V. J., Davidson, L., Williams, J., \& Slade, M. (2011). What does recovery mean in practice? A qualitative analysis of international recovery-oriented practice guidance. Psychiatric Services, 62, 1470-1476, https://dx.doi.org/10.1176/ appi.ps.001312011.

McCaffrey, T. (2014). Experts by experience' perspectives of music therapy in mental healthcare: A multi-modal evaluation through art, song and words. University of Limerick. Unpublished doctoral thesis, Available from, http://ulir.ul.ie/handle/10344/4241.

McCaffrey, T., \& Edwards, J. (2015). Meeting art with art: Arts based methods enhance researcher reflexivity in research with mental health service users. Journal of Music Therapy, 52, 515-532, https://doi.org/10.1093/jmt/thv016.

McCaffrey, T., \& Edwards, J. (2016). Music therapy helped me get back doing: Using interpretative phenomenological analysis to illuminate the perspectives of music therapy participants in mental health services. Journal of Music Therapy, 53, 121-148, https://doi.org/10.1093/jmt/thw002.

McCaffrey, T., Edwards, J., \& Fannon, D. (2011). Is there a role for music therapy in the recovery approach in mental health? The Arts in Psychotherapy, 38, 185-189, http://dx.doi.org/10.1016/j.aip.2011.04.006.

Mental Health "Recovery" Study Working Group. (2009). Mental health "recovery": Users and refusers. Toronto, Canada: Wellesley Institute.

Morant, N. (2006). Social representations and professional knowledge: The representation of mental illness among mental health practitioners. British Journal of Social Psychology, 45, 817-838, https://dx.doi.org/10.1348/014466605X81036.

National Institute for Health and Care Excellence (NICE) (2011). Service user experience in adult mental health: improving the experience of care for people using adult NHS mental health services. Clinical guidelines [CG136]. Retrieved from https://www.nice.org.uk/guidance/ $\operatorname{cg} 136$

Ness, O., Borg, M., Semb, R., \& Karlsson, B. (2014). "Walking alongside:" Collaborative practices in mental health and substance use care. International Journal of Mental Health Systems, 8(1), 55, https://dx.doi.org/10.1186/1752-4458-8-55.

Pedersen, I. N. (2014). Music therapy in psychiatry today - do we need specialization based on the reduction of diagnosis-specific symptoms or on the overall development of patients' resources? Or do we need both? Nordic Journal of Music Therapy, 23, 173-194, http://dx.doi.org/10.1080/08098131.2013.790917.

Onken, S. J., Craig, C. M., Ridgway, P., Ralph, R. O., \& Cook, J. A. (2007). An analysis of the definitions and elements of recovery: a review of the literature. Psychiatric Rehabilitation Journal, 31(1), 9-22, http://dx.doi.org/10.2975/31.1.2007.9.22.

Pilgrim, D., \& McCranie, A. (2013). Recovery and mental health: A critical sociological account. Hampshire, UK: Palgrave Macmillan. https://doi.org/10.1007/978-1-137-35889-9.

Priebe, S., Omer, S., Giacco, D., \& Slade, M. (2014). Resource-oriented therapeutic models in psychiatry: Conceptual review. The British Journal of Psychiatry, 204(4), 256-261, https://dx.doi.org/10.1192/bjp.bp.113.135038.

Priestley, M. (1994). Essays on analytical music therapy. Gilsum, NH: Barcelona Publishers. 
Repper, J. (2000). Adjusting the focus of mental health nursing: Incorporating service users' experiences of recovery. Journal of Mental Health, 9, 575-587, https://dx.doi.org/10.1177/ 1476750314534997.

Repper, J., \& Perkins, R. (2003). Social inclusion and recovery: A model for mental health practice. Edinburgh, Scotland: Baillière Tindall.

Ridgway, P. (2001). Restorying psychiatric disability: Learning from first person recovery narratives. Psychiatric Rehabilitation Journal, 24, 335-343, https://dx.doi.org/10.1037/ h0095071.

Rolvsjord, R. (2004). Therapy as empowerment. Nordic Journal of Music Therapy, 13, 99-111, http://dx.doi.org/10.1080/08098130409478107.

Rolvsjord, R. (2010). Resource-oriented music therapy in mental health care. Gilsum, NH: Barcelona Publishers.

Rolvsjord, R. (2013). Music therapy in everyday life, with 'the organ as the third therapist. In L. O. Bonde, E. Ruud, M. Skånland, \& G. Trondalen (Eds.), Musical life stories: Narratives on health musicking (pp. 201-220). Oslo: Centre for Music and Health Publication Series, NMHpublikasjoner.

Rolvsjord, R., Gold, C., \& Stige, B. (2005). Reserach rigour and therapeutic flexibility: Rationale for a therapy manual developed for a randomised controlled trial. Nordic Journal of Music Therapy, 14, 15-32, http://dx.doi.org/10.1080/08098130509478122.

Rose, D. (2014). The mainstreaming of recovery. Journal of Mental Health, 23(5), 217-218, http://dx.doi.org/10.3109/09638237.2014.928406.

Shepherd, G., Boardman, J., \& Slade, M. (2008). Making recovery a reality. London, England: Sainsbury Centre for Mental Health.

Slade, M. (2009). 100 ways to support recovery. London, England: Rethink. http://www.mentalhealthrecovery.com/recovery-resources/documents/ 100_ways_to_support_recovery1.pdf.

Slade, M., Amering, M., \& Oades, L. (2008). Recovery: An international perspective. Epidemiologia e Psichiatria Sociale, 17(2), 128-137, https://dx.doi.org/10.1017/ S1121189X00002827.

Slade, M., Adams, N., \& O’Hagan, M. (Eds.). (2012). Recovery around the globe. International Review of Psychiatry, Special issue, 24(1), 1-78, https://doi.org/10.3109/ 09540261.2011 .644847$.

Slade, M., \& Wallace, G. (2017). Recovery and mental health. In M. Slade, L. Oades, \& A. Jarden (Eds.), Wellbeing, recovery and mental health (pp. 24-34). Cambridge, England: Cambridge University Press.

Solli, H. P. (2014). The groove of recovery; A qualitative study of how patients diagnosed with psychosis experience music therapy. University of Bergen, Norway. Unpublished doctoral thesis, Available from, http://bora.uib.no/handle/1956/8753.

Solli, H. P. (2015). Battling illness with wellness: a qualitative case study of a young rapper's experiences with music therapy. Nordic Journal of Music Therapy, 24, 204-231, https://dx.doi.org/10.1080/08098131.2014.907334.

Solli, H. P., \& Rolvsjord, R. (2015). "The opposite of treatment": A qualitative study of how patients diagnosed with psychosis experience music therapy. Nordic Journal of Music Therapy, 24, 67-92, https://dx.doi.org/10.1080/08098131.2014.890639.

Solli, H. P., Rolvsjord, R., \& Borg, M. (2013). Toward understanding music therapy as a recovery-oriented practice within mental health care: A meta-synthesis of service users' experiences. Journal of Music Therapy, 50, 244-273, https://dx.doi.org/10.1093/jmt/ 50.4.244.

Stige, B., \& Aarø, L. (2012). Invitation to community music therapy. New York, NY: Routledge.

Telford, R., \& Faulkner, A. (2004). Learning about service user involvement in mental health research. Journal of Mental Health, 13, 549-559, https://dx.doi.org/10.1080/ 09638230400017137. 
Turner-Crowson, J., \& Wallcraft, J. (2002). The recovery vision for mental health services and research: A British perspective. Psychiatric Rehabilitation Journal, 25, 245-254, http://psycnet.apa.org/doi/10.1037/h0095018.

Vaillancourt, G. (2012). Music therapy: A community approach to social justice. The Arts in Psychotherapy, 39, 173-178, http://dx.doi.org/10.1016/j.aip.2011.12.011.

World Health Organisation. (2013). Mental health action plan 2013-2020. (9241506024).

Geneva, Switzerland: World Health Organization. Retrieved from http://apps.who.int/iris/ bitstream/10665/89966/1/9789241506021_eng.pdf. 